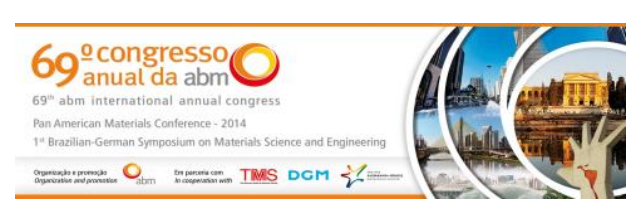

Tema: Gestão de Manutenção

\title{
PLANEJAMENTO DE GRANDES REFORMAS DE USINAS DE PELOTIZAÇÃO UTILIZANDO A METODOLOGIA DE GERENCIAMENTO DE PROJETOS IPA (INDEPENDENT PROJECT ANALYSIS)*
}

Bruno Miranda de Miranda ${ }^{1}$ Manoel José Pedrosa filho² João Guilherme da $\mathrm{Cruz}^{3}$

\section{Resumo}

O Trabalho proposto demonstra os avanços dos resultados das grandes reformas de usinas de pelotização da empresa Samarco Mineração, unidade industrial de UBU, utilizando de forma sistêmica a metodologia de gerenciamento de projetos IPA (Independent Project Analysis). Através da metodologia obteve-se maior envolvimento e integração dos stakeholders e canais de processo com foco na segurança, saúde e meio ambiente. Outros fatores relevantes foram o aumento da utilização de recursos próprios, modificações de estratégia de contratação e análise crítica das paradas com aprendizado contínuo. Neste trabalho apresentaremos a definição do processo com fundamentação teórica e determinantes de excelência, incluindo os indicadores e resultados obtidos através do método, como indicadores de desenvolvimento abordamos os principais pilares da manutenção, sendo eles: segurança, custo, prazo, acurácia e produção.

Palavras-chave: TFEL; Gerenciamento de projeto; Paradas gerais.

\section{PELLETIZING PLANTS TURNAROUND PLANNING, USING THE IPA (INDEPENDENT PROJECTS ANALYSIS) MANAGEMENT PROJECTS METHODOLOGY}

\section{Abstract}

The main purpose of this paper is to demonstrate the progress and outcomes of the major reforms of the pelletizing plants at Samarco Mining Company, UBU industrial unit, using the IPA- Management Projects Methodology. Through this methodology, greater involvement and integration among stakeholders were achieved as well as process channels with focus on safety, health and environment. Other important facts were the increase by using own resources, hiring strategy modifications and the turnaround critical analysis. The process definition will be presented with theoretical basis and excellence aspects, including the indicators and results obtained by the method. Regarding development indicators, we worked on the following maintenance key issues: safety, cost, time, accuracy and production. Inserir a versão do resumo para o idioma inglês, sem uso de parágrafo.

Keywords: TFEL; Project management; Turn around.

1 Tecnólogo Mecânico, Planejador de Manutenção, Departamento de planejamento de manutenção, Samarco Mineração S/A, Anchieta, ES, Brasil.

2 Co-autor, Engenheiro Mecânico, Chefe de equipe planejamento de manutenção, Departamento de planejamento de manutenção, Samarco Mineração S/A, Anchieta, ES, Brasil.

3 Co-autor, Engenheiro Químico, Analista de Projeto Independent Project Analysis Latin America Ltda., Curitiba, PR, Brasil.

\footnotetext{
* Contribuição técnica ao 69 Congresso Anual da ABM - Internacional e ao 14ํㅡㄹ ENEMET - Encontro Nacional de Estudantes de Engenharia Metalúrgica, de Materiais e de Minas, 21 a 25 de julho de 2014, São Paulo, SP, Brasil.
} 


\section{INTRODUÇÃO}

\subsection{Apresentação do Caso}

O estudo de caso objeto deste trabalho é o planejamento da Parada Geral a frio das Usinas de Pelotização de Minério de Ferro da Samarco Mineração S.A, situada em Ponta Ubu, Anchieta, ES.

As Paradas Gerais de usinas de Pelotização possuem a duração determinada pelo caminho crítico, ou seja, atividade que não tem folga e tem a maior duração.

O Principal evento da manutenção é a parada geral á frio, em que serão realizados serviços de manutenção planejados, melhoria e projetos de capital, também chamados de TIE-IN com a planta parada sem produção, ou seja, o forno está com a temperatura ambiente.

A Gerência de Manutenção, alinhada aos desafios da Companhia, tais como: Reduzir custos e despesas; aumentar a eficiência dos processos produtivos; garantir a eficiência dos processos fundamentais e de suporte de forma alinhada às necessidades do negócio; ser eficiente na gestão de projetos; aumentar a produtividade sistêmica de mão de obra, buscou metodologia de auditoria no mercado externo, a consultoria do Instituto IPA (Independent Project Analysis), para que o seu processo de Parada Geral fosse comparado com as melhores práticas a nível mundial.

\subsection{Objetivo}

O objetivo deste trabalho é documentar o planejamento, execução e controle de grande parada de manutenção da Samarco Mineração S.A. na unidade de Ponta Ubu Anchieta, ES, para execução de serviços de manutenção, melhorias de processos e instalação de investimento de capital na planta industrial, utilizando o método de gerenciamento de projeto do instituto IPA (Independent Project Analysis).

\section{MATERIAIS E MÉTODOS}

\subsection{Parada Geral de Manutenção e Projeto}

Projeto é descrito pelo PMBOK Guide 2008 como: "Um projeto é um esforço temporário empreendido para criar um produto, serviço ou resultado exclusivo".

Segundo Casarotto, o Projeto pode ser caracterizado por um conjunto de atividades inter-relacionadas visando um objetivo comum. Caracteriza-se ainda por ser executado dentro de um determinado prazo e conforme um custo previamente estimado.

Devido suas características, uma Parada Geral de Manutenção também é um Projeto, diferente das manutenções rotineiras.

\subsection{O Instituto IPA (Independent Project Analysis)}

O IPA (Independent Project Analysis, Inc) é líder em pesquisa e consultoria em gestão de projetos e paradas.

O instituto IPA foi criado para oferecer programas de educação baseados no trabalho de pesquisa e consultoria IPA com centenas de empresas.

\footnotetext{
* Contribuição técnica ao $69^{\circ}$ Congresso Anual da ABM - Internacional e ao 14ํㅡㄹ ENEMET - Encontro Nacional de Estudantes de Engenharia Metalúrgica, de Materiais e de Minas, 21 a 25 de julho de 2014, São Paulo, SP, Brasil.
} 


\subsection{Metodologia IPA}

O método "TFEL-Turnaround Front End Loading" foi desenvolvido pela empresa IPA. Em linhas gerais, o método descreve um conjunto de práticas de planejamento que aumentam a chance de sucesso de uma Grande Parada (ou Turnaround em inglês), ou seja, o atendimento a indicadores pré-estabelecidos de prazo, custo e segurança. A IPA já realizou centenas de estudos de pesquisa que relacionam práticas de projeto e/ou de parada a resultados utilizando bancos de dados de mais de 16.000 projetos de capital e 400 paradas.

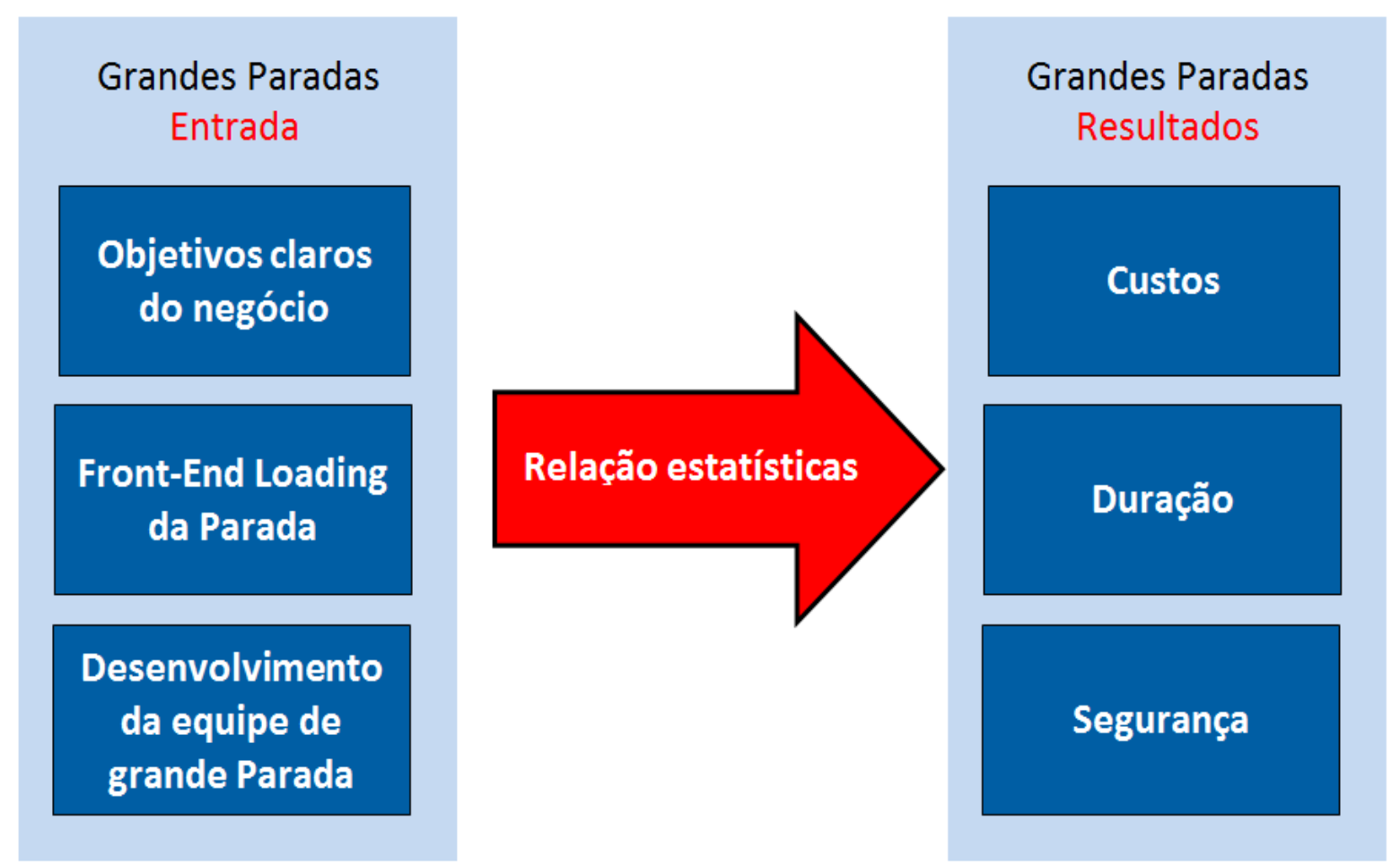

Figura 1. Visão Geral do Método IPA.

\subsubsection{Objetivos claros do negócio}

O objetivo do negócio representa resultados em termos do negócio, por exemplo: aumentar as taxas de produção em 5 por cento, aumentar os ciclos de parada para 2 anos.

A metodologia avalia:

- Escopo versus objetivos do negócio versus custo e cronograma.

- O atendimento do escopo aos objetivos do negócio e ao alinhamento com as metas de duração, perda de produção e ao orçamento.

- A duração, perda de produção e estimativas de custo, devem ser apropriadas ao escopo e consistentes com o objetivo do negócio.

\subsubsection{Front-End Loading da parada}

O planejamento de cada parada é avaliado de acordo com a aderência as melhores práticas e recebe uma pontuação chamada "Índice TFEL", também chamado de "Índice de desenvolvimento do planejamento".

O índice TFEL avalia três componentes principais, a definição do escopo, a estratégia de execução e o status do planejamento, estes componentes são subdivididos em outros conforme figura 2.

* Contribuição técnica ao $69^{\circ}$ Congresso Anual da ABM - Internacional e ao 14ํㅡㄹ ENEMET - Encontro Nacional de Estudantes de Engenharia Metalúrgica, de Materiais e de Minas, 21 a 25 de julho de 2014, São Paulo, SP, Brasil. 
oferece o serviço de medição meses antes da Parada, para que se possa verificar melhoras na medição final.

A figura 3 mostra a evolução do índice TFEL no decorrer do tempo.

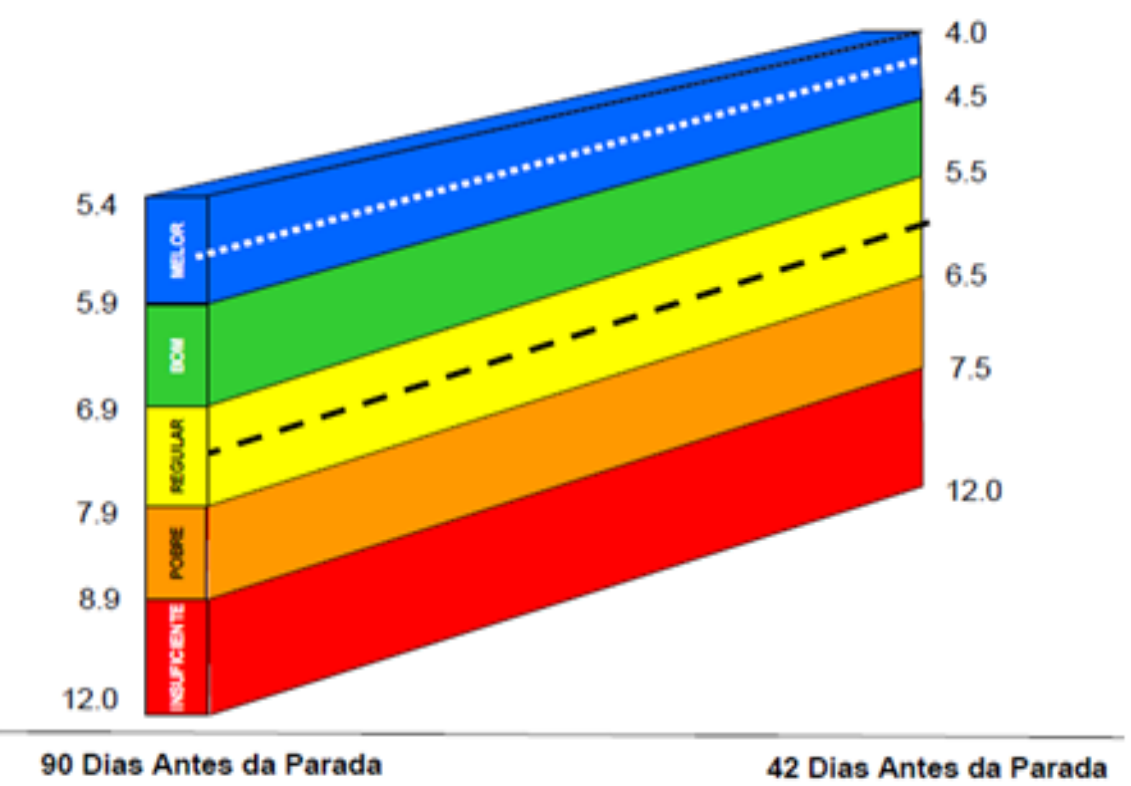

Figura 3. Evolução do TFEL no decorre do tempo - IPA.

\subsubsection{Fases de aprovação da parada}

As fases de aprovação do Comitê Diretor são regidas pelos entregáveis do plano mestre adaptado à metodologia do IPA, as quais seguem de forma resumida na Figura 4:

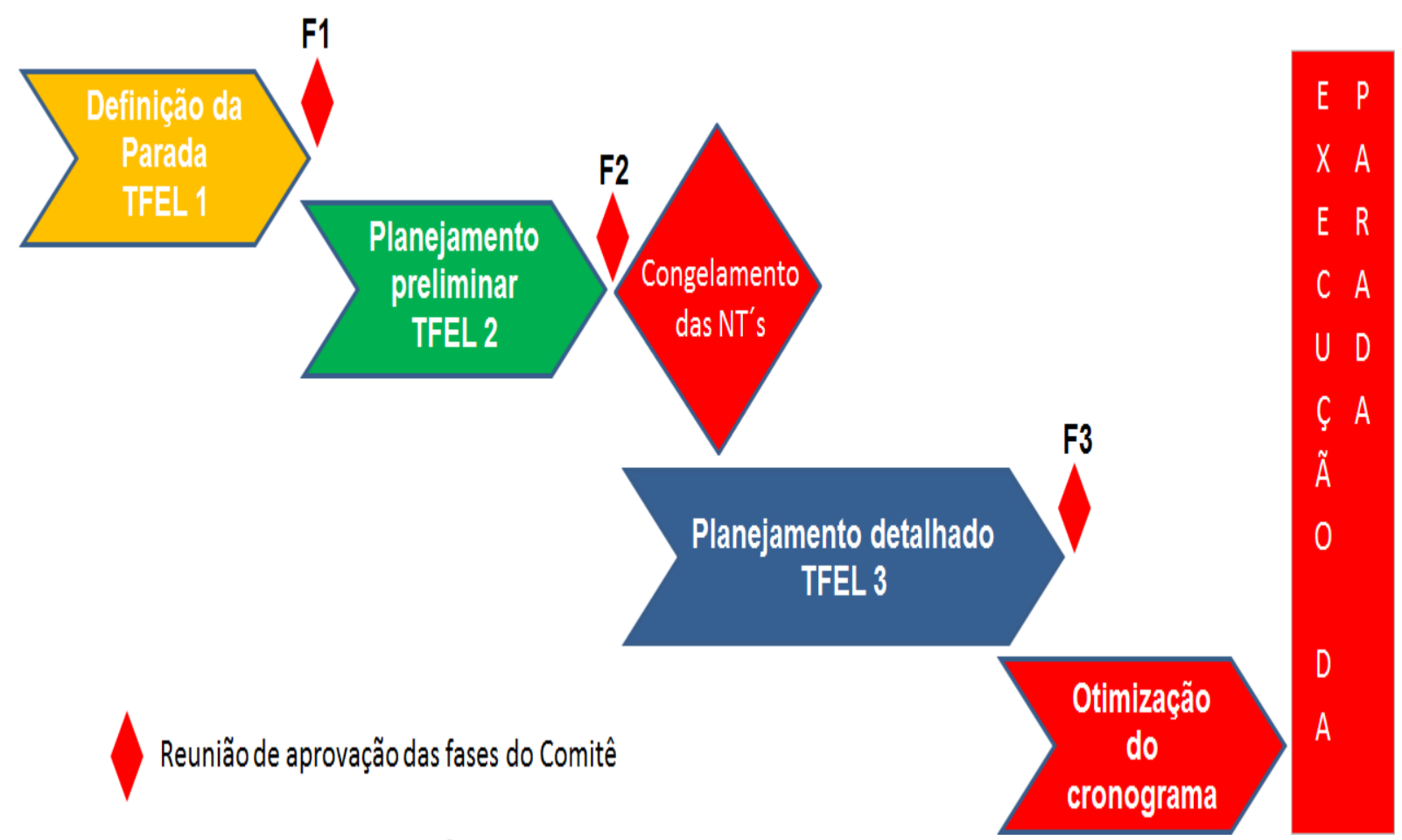

Figura 4. Fases de aprovação da Parada

\footnotetext{
* Contribuição técnica ao $69^{\circ}$ Congresso Anual da ABM - Internacional e ao 14ํㅡㄹ ENEMET - Encontro Nacional de Estudantes de Engenharia Metalúrgica, de Materiais e de Minas, 21 a 25 de julho de 2014, São Paulo, SP, Brasil.
} 


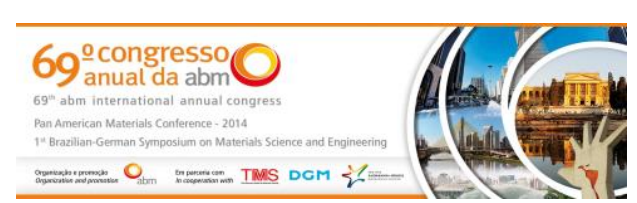

\subsection{TFEL 1 - Definição da parada}

É a fase de definição da Parada, onde todos os "stakeholders" (Partes interessadas) terão uma visão gerencial do projeto.

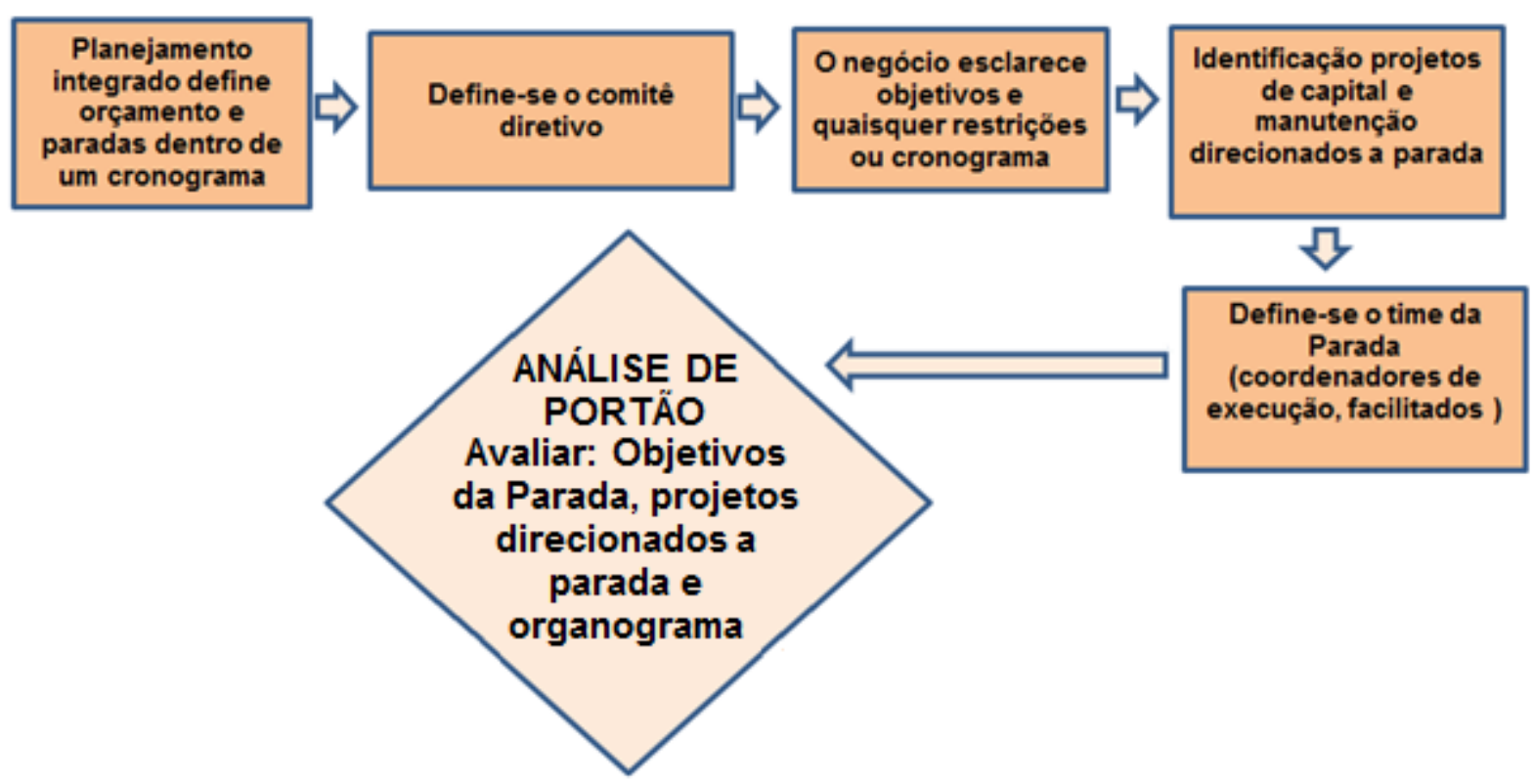

Figura 5. Fluxograma fase 01 TFEL 1

\subsection{Termo de abertura do projeto}

O Termo de abertura do Projeto é um documento elaborado na fase de TFEL 1 e contém as seguintes informações:

- Esclarecer e comunicar os objetivos da Parada;

- Instalar comitê diretor, que é multidisciplinar e composto pela alta liderança da unidade. Este Comitê terá o poder de aprovar ou reprovar o planejamento, tornando-o oficial através de reuniões de "Aprovação de Portão", que acontece no final de cada fase do Projeto;

O comitê é composto pelos seguintes colaboradores: Gerente Geral de Operações, Gerente de Manutenção, Gerente de Produção, Gerente de Materiais, Gerente de Serviços Contratados, Gerente de Segurança do Trabalho, Gerente de Planejamento Integrado, Gerente de Meio Ambiente, Gerente Engenharia Processo e Automação, Gerente de Infraestrutura, Gerente de Engenharia de Projetos e Coordenadores de Projetos de Capital.

- Definir as metas a serem cumpridas durante o Projeto, tais como: desvio dos Custos (Planejados x Realizados); desvio AP/AS (Atividades planejadas $x$ extras solicitadas); desvio AP/AR (Atividades planejadas $x$ realizadas); desvio de Prazo (Duração planejada x realizada); desvio de Segurança e Meio Ambiente (Itens conformes $x$ itens não conformes), aderência ao orçamento detalhado, aderência ao calendário de paradas divulgado a todos os stakeholders da parada, índice de Retrabalho, produtividade do Forno [ton/m2 grelha], índice Global de Qualidade de Fornecedores, meta de disponibilidade real, diretrizes estratégicas de custo;

- Definir os principais marcos do projeto;

- Definir o orçamento total do projeto estratificado pelas principais áreas e separado por categorias: serviços contratos e materiais, conforme demostrado na Figura 6;

\footnotetext{
* Contribuição técnica ao $69^{\circ}$ Congresso Anual da ABM - Internacional e ao 14ํㅡㄹ ENEMET - Encontro Nacional de Estudantes de Engenharia Metalúrgica, de Materiais e de Minas, 21 a 25 de julho de 2014, São Paulo, SP, Brasil.
} 


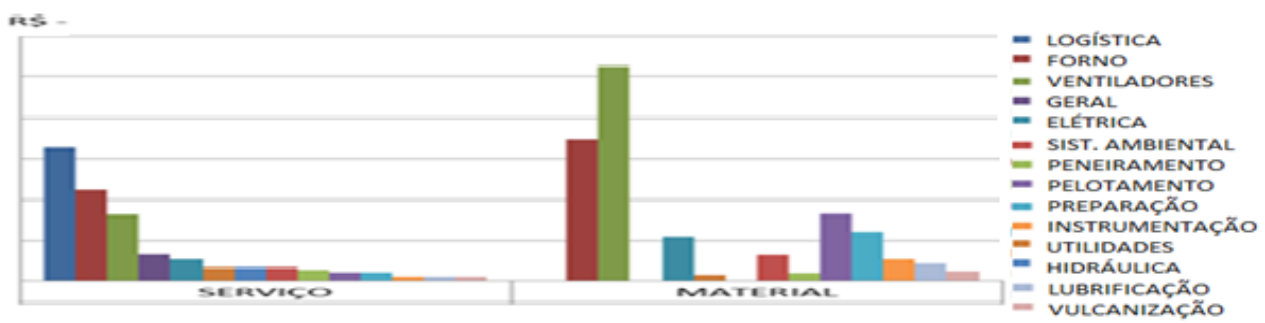

Figura 6. Orçamento da parada.

- Definir a equipe do projeto, em forma de organograma, contendo o nome e contato dos coordenadores de execução e facilitadores da Parada; e

- Identificar a existência de Projetos de Capital que serão executados durante o Projeto da Parada Geral da Usina e mapear de forma macro as possíveis interferências.

\subsection{TFEL 2 - Definição da Parada}

É a fase de planejamento preliminar da Parada. As principais entregas são: definir o escopo, definir a estratégia de contratação, estimar os custos, cronograma preliminares, plano de coleta de resíduos preliminar, histograma preliminar, follow up de material e serviços, plano de gerenciamento de mudanças, plano preliminar de segurança e plano de comunicação. Segue o resumo desta fase no fluxograma representado na Figura 7.

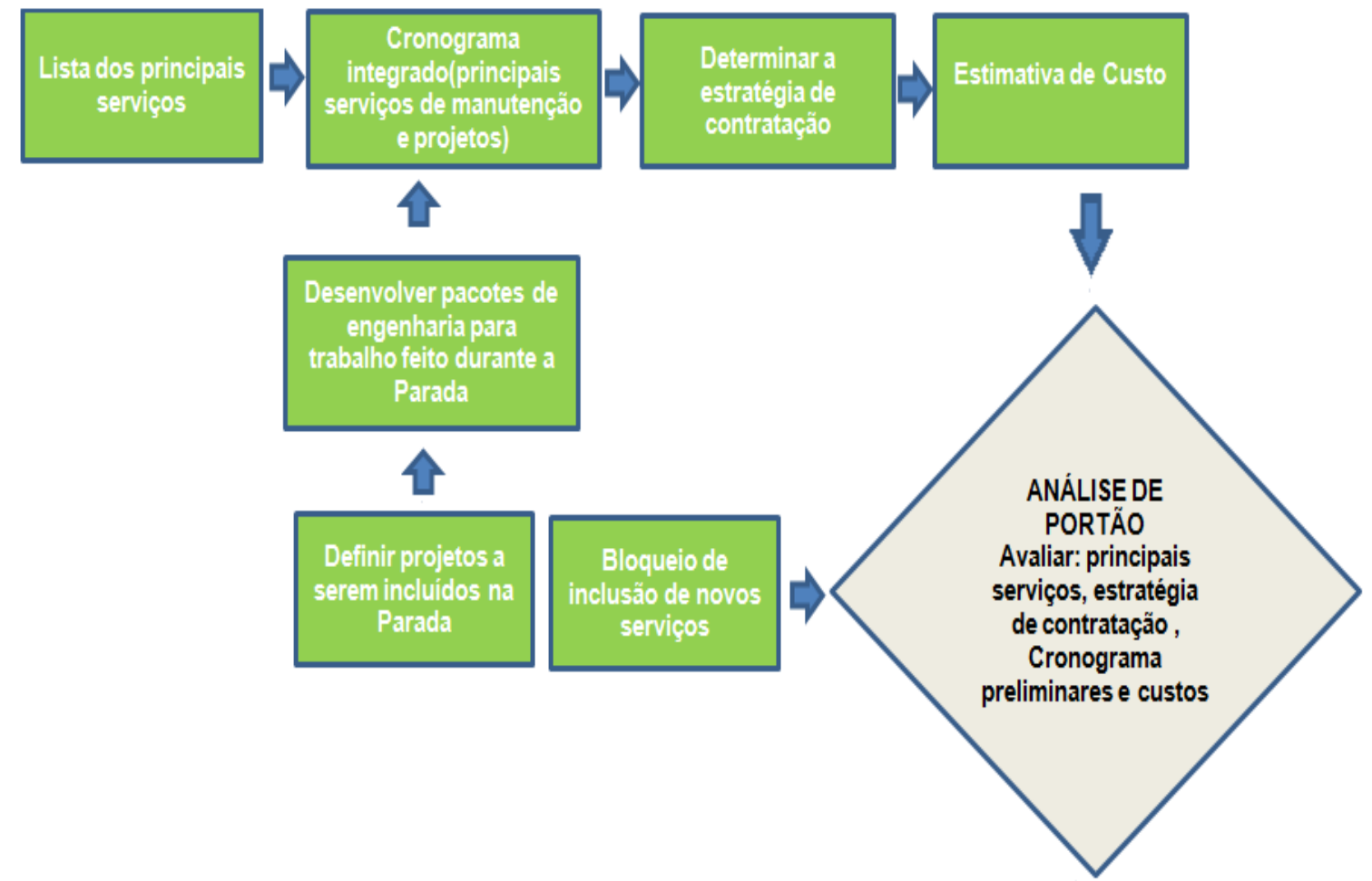

Figura 7. Fluxograma fase 02 TFEL 2.

\subsection{Definição do escopo}

A equipe de planejamento da Parada, irá realizar reuniões setoriais com todas as partes interessadas, com foco em definir todas as demandas de serviços provenientes de: padrões pré-estabelecidos por planos de manutenções preventivas, serviços provenientes de laudos de inspeções preditivas, melhorias provenientes do

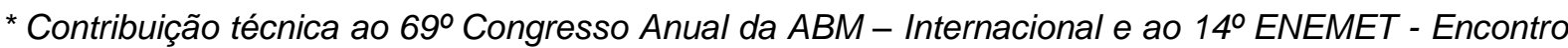
Nacional de Estudantes de Engenharia Metalúrgica, de Materiais e de Minas, 21 a 25 de julho de 2014, São Paulo, SP, Brasil.
} 


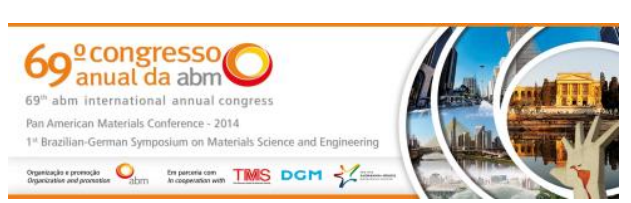

Departamento de Engenharia de Manutenção, da Gerência de Projetos, da Gerência de Produção e da Gerência de Segurança do Trabalho.

Após validação da lista pelos gestores das áreas de planejamento, produção, inspeção e execução, novos serviços deverão ser submetidos ao Plano de Gerenciamento de Mudança do Escopo

\subsection{Plano de gerenciamento de mudança do escopo}

O Plano de gerenciamento de mudança do escopo tem o objetivo de mostrar como serão tratadas as mudanças no escopo da parada de Usina. Após a data do congelamento, novos serviços só poderão ser executados após a aprovação gerencial do formulário SSE (Solicitação de Serviços Extras), onde deverão ser analisados os seguintes impactos na Parada:

- Alteração do prazo final;

- Aumento no custo da parada;

- Disponibilidade de recursos extras;

- Tempo hábil para planejamento, contratação de serviços e aquisição de materiais.

Conforme demostrado na Figura 8, o cumprimento rigoroso do plano de Gerenciamento de Mudanças produz Paradas com custos mais previsíveis.

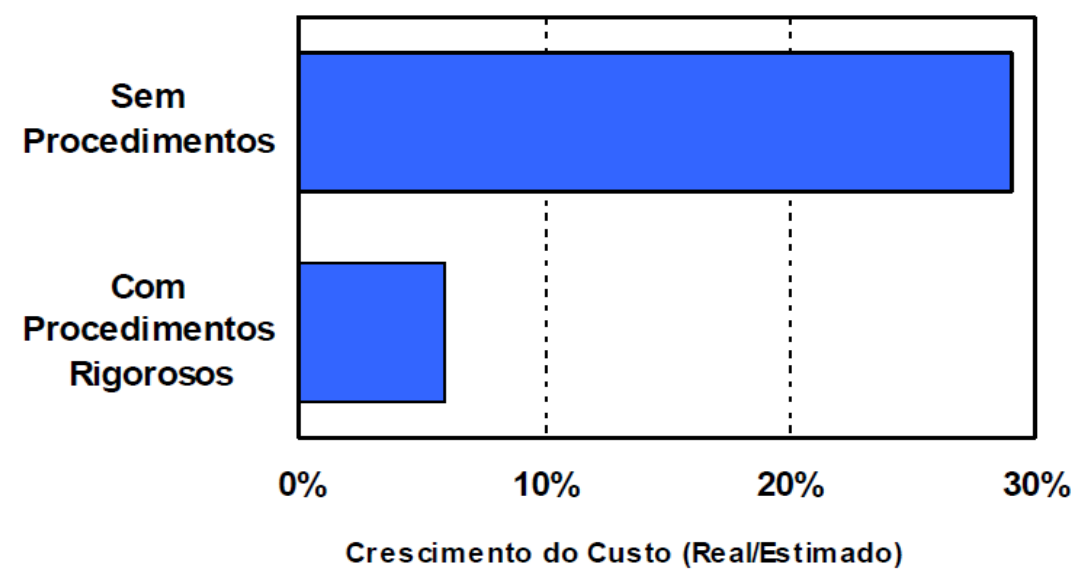

Figura 8. Fluxograma fase 02 TFEL 2

\subsection{Cronogramas preliminares integrados}

Após o congelamento do escopo, o planejamento preliminar das atividades que compõem os serviços deverão ser carregados no cronograma e todos os recursos tais como: guindastes, compressores, caminhões, andaimes, colaboradores e etc., deverão ser nivelados maximizando ao máximo sua utilização.

\subsection{Plano de segurança}

Este documento tem o objetivo de divulgar os procedimentos de içamento de cargas, trabalhos em altura, trabalhos em espaço confinado a escala e área de atuação dos técnicos de segurança, check list de segurança e mapeamento de trabalhos sobrepostos, para prover informações suficientes para um bom planejamento de segurança e evitar a ocorrência de acidentes.

\footnotetext{
* Contribuição técnica ao $69^{\circ}$ Congresso Anual da ABM - Internacional e ao 14ํㅡㄹ ENEMET - Encontro Nacional de Estudantes de Engenharia Metalúrgica, de Materiais e de Minas, 21 a 25 de julho de 2014, São Paulo, SP, Brasil.
} 


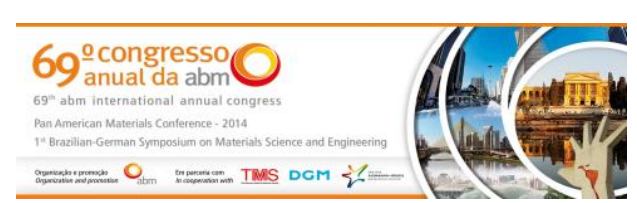

\subsection{Plano de controle de resíduos}

Este documento tem o objetivo de orientar os participantes da Parada sobre as normas internas de controle de resíduos baseadas na NBR 10.004/2004 e os principais pontos de coletas e descarte de materiais.

\subsection{Plano de contratação}

Este documento visa determinar as estratégias de contratação de mão-de-obra para atendimento as Paradas de Usina de Pelotização na Unidade de Ponta de Ubu, uma vez que esta demanda não pode ser absorvida pelo quadro fixo da manutenção. $O$ plano tem ainda por objetivo orientar o monitoramento do desempenho dos fornecedores que irão atender às necessidades do projeto.

\subsection{Plano de comunicação}

Este documento tem o objetivo de englobar todos os elementos para a geração, a coleta, a disseminação e o armazenamento das informações do projeto, mitigando as principais falhas.

Resultados esperados:

- Aumentar o controle gerencial

- Otimizar as decisões

- Antecipar as decisões desfavoráveis

\subsection{TFEL 3 - Planejamento detalhado}

É a fase de planejamento detalhado da Parada. No final desta fase será avaliado o planejamento detalhado dos recursos, cronogramas definitivos, levantamento final dos custos, histograma estimado, fechamento dos processos de aquisição, apresentação das respostas dos riscos identificados. Segue o resumo desta fase no fluxograma representado na Figura 9

\footnotetext{
* Contribuição técnica ao $69^{\circ}$ Congresso Anual da ABM - Internacional e ao 14ํㅡㄹ ENEMET - Encontro Nacional de Estudantes de Engenharia Metalúrgica, de Materiais e de Minas, 21 a 25 de julho de 2014, São Paulo, SP, Brasil.
} 


\section{RESULTADOS}

As Figuras 10,11,12 e 13 apresentam a evolução dos resultados das Paradas de Usina das plantas de pelotização de 2010 a 2014. Os ganhos obtidos convergem para as necessidades da organização.
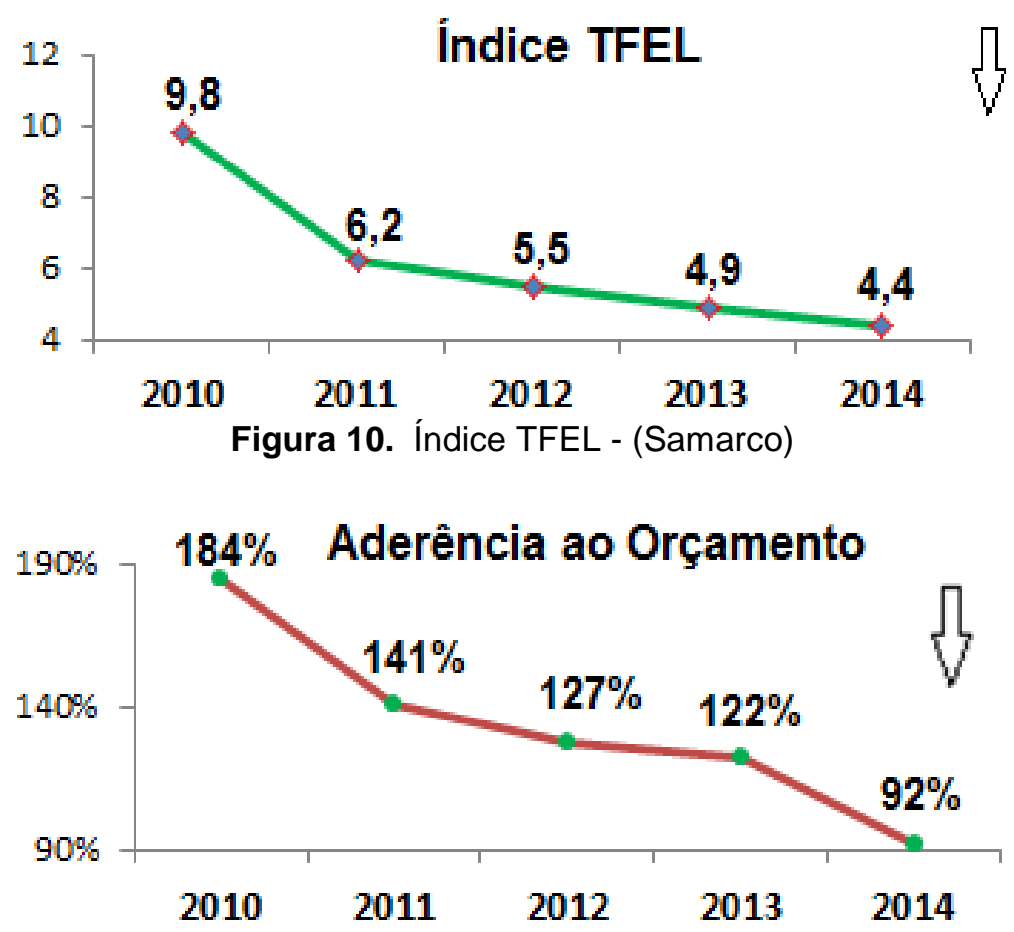

Figura 11. Aderência ao orçamento (Samarco)

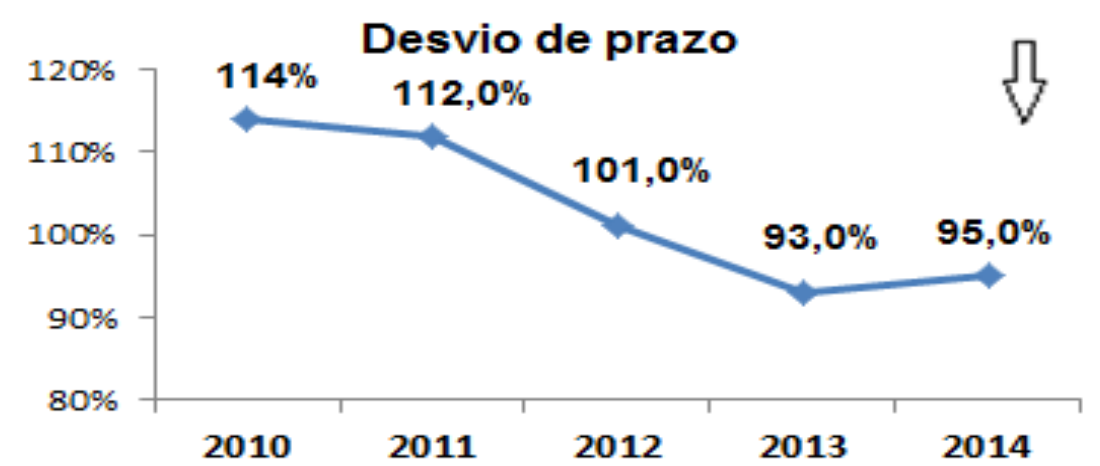

Figura 12. Desvio de Prazo - (Samarco)

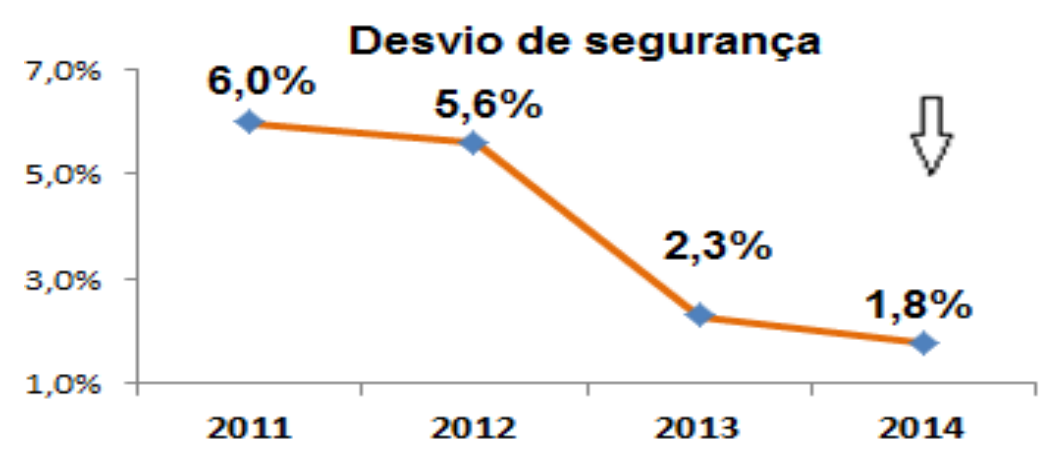

Figura 13. Percentual de desvios de Segurança

\footnotetext{
* Contribuição técnica ao 69ำ Congresso Anual da ABM - Internacional e ao 14ํㅡㄹ ENEMET - Encontro Nacional de Estudantes de Engenharia Metalúrgica, de Materiais e de Minas, 21 a 25 de julho de 2014, São Paulo, SP, Brasil.
} 


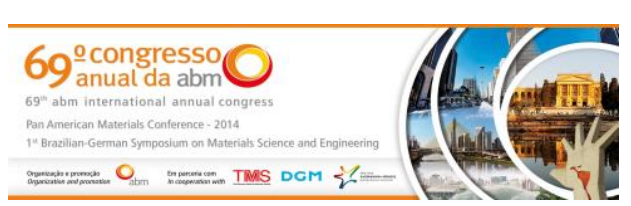

Outros ganhos percebidos no final do projeto são: envolvimento dos fornecedores nos aspectos de segurança, saúde e meio ambiente, maior integração dos stakeholders, envolvimento das equipes de execução e inspeção na fase de "planejamento preliminar", capacitação das equipes, elaboração de "Contratos Críticos", maior utilização de "Recursos Próprios", estratégias de Contratações, incluindo "Indicadores de Performance" e análise crítica das Paradas de Usinas.

\section{CONCLUSÃo}

A metodologia apresentada neste trabalho pode ser aplicada a qualquer parada geral nos diversos tipos de seguimentos industriais.

Uma parada que apresente uma definição melhor do que a média da indústria bem antes da data da execução da Parada resulta em custos e resultados de cronogramas mais previsíveis. Desta forma, melhorar o TFEL leva a paradas mais previsíveis, efetivas e, por conseguinte, a melhoria dos cronogramas de desligamento e de custo resulta em maior disponibilidade da planta e mais receita.

\section{Agradecimentos}

Gostaria de expressar meus agradecimentos aos gestores da Samarco Mineração S.A.: Sérgio Gonçalves Mileipe, Fausto Melo, Leandro Silva Leite, a equipe de Planejamento de manutenção da Samarco Mineração S.A.: Aldiéres Cerruti, Bruno Rovetta, Crystian Augusto, Deivisson Campos, Fabiano Miranda, Filipe Simões, Ivan Zuqui, Julio Monsores, Marcos Pagotto, Raphael Frauches, Raphael Moledo, Roney Marques, Vinicius Avelar e Wellington Banhos.

\section{BIBLIOGRAFIA}

1 Casarotto FN, Fávero JS, Castro JEE. Gerência de Projeto/ Engenharia simultânea. São Paulo: Atlas; 1999.

2 Kerzner H. Gestão de Projetos. São Paulo: Saraiva; 2008.

3 Maximiano N, Amaru AC. Administração de Projetos: Como transformar ideias em resultados. São Paulo: Atlas; 2009.

4 Project Manangement Institute. Um Guia do conhecimento em Gerenciamento de Projetos: Guia PMBOK. USA: Project Manangement Institute; 2008.

5 Verri LA. Sucesso em Paradas de Manutenção. Rio de janeiro: Qualimark; 2008.

6 Indepent Project Analysis - IPA. Práticas de Paradas Mais Curtas e de Custo Mais Efetivo [apostila treinamento externo da Samarco Mineração]. IPA; jun. 2010.

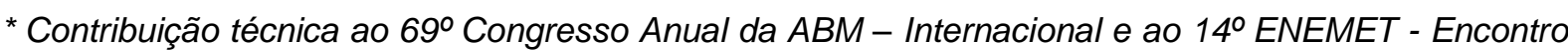
Nacional de Estudantes de Engenharia Metalúrgica, de Materiais e de Minas, 21 a 25 de julho de 2014, São Paulo, SP, Brasil.
} 